Part of Journal of Research of the National Bureau of Standards, Volume 26, January 194

\title{
PREPARATION OF $d$-MANNOSE
}

\author{
By Horace S. Isbell
}

ABSTRACT

An improved method for the preparation of $d$-mannose from ivory-nut shavings is reported. This method differs from previous ones in that the sugar is crystallized from a mixture of methyl and isopropyl alcohols. The yield of crystalline sugar, based on the weight of ivory-nut shavings, is approximately 35 percent.

Although several investigators $[1,2,3,4,5,6,7]^{1}$ have given directions for the preparation of $d$-mannose from ivory-nut turnings, obtained from button factories, the methods are not entirely satisfactory. Various workers have prepared large quantities of mannose by the method of Hudson and Sawyer [3]; but, as pointed out by Hudson and Jackson [7], the results have not been consistently good. Hudson and Jackson sought to improve the method by first preparing pure crystalline $\alpha$-methyl $d$-mannoside from vegetable ivory and then converting the pure glycoside to $d$-mannose. The process, although successful, requires two hydrolyses and considerable labor. At various times during the past 10 years the writer has had occasion to prepare crystalline d-mannose and has made certain improvements in the method. With these improvements it is possible to obtain consistently good results in the preparation of the sugar without the intermediate preparation of the methyl glycoside or other derivative. The method used is similar to that described by Clark [4] but differs in that the sugar solution is purified by precipitation of impurities with a mixture of methyl and isopropyl alcohol.

Method.-One kilogram of screened ivory-nut shavings ${ }^{2}$ is mixed with $1 \mathrm{~kg}$ of cold 75-percent sulfuric acid $(430 \mathrm{ml}$ of concentrated sulfuric acid and $250 \mathrm{ml}$ of water). The material is triturated until the sulfuric acid is uniformly distributed, and allowed to stand until the next day, preferably at about $35^{\circ} \mathrm{C}$. The mass is then dissolved in 10 liters of water, and the solution is filtered through cheesecloth. The filtrate is heated to boiling for 6 hours while the volume is maintained approximately constant. The hot liquid is then neutralized with barium carbonate, using a commercial antifoam agent or capryl alcohol to reduce foaming. After the addition of $200 \mathrm{~g}$ of a decolorizing carbon, the barium sulfate is allowed to settle and is separated by filtration. The filtrate is evaporated in vacuo to a sirup of about 85-percent total solids $\left(n_{D}^{20}=1.503\right)$. This sirup is thoroughly mixed with 1 liter of warm methyl alcohol, after which

\footnotetext{
1 Figures in brackets indicate the literature references at the end of this paper.

2 The ivory-nut shavings may be purchased from the Button Machinery Co., 11th, Grand,"and Adams Street, Hoboken, N. J.
} 
the solution is diluted with 2 liters of isopropyl alcohol. ${ }^{3}$ This results in the precipitation of some gummy amorphous material, which is separated by decantation. The larger part of the mannose is in the alcoholic extract; that in the gummy residue is separated by triturating the gum with $250 \mathrm{ml}$ of methyl alcohol and then adding $500 \mathrm{ml}$ of isopropyl alcohol. The mixture is allowed to settle, and the insoluble residue is separated from the alcoholic extract. The residue thus obtained is given a second treatment with methyl and isopropyl alcohols, and the alcoholic extracts are combined. After the addition of about $50 \mathrm{~g}$ of a decolorizing carbon, the solution is filtered and evaporated in vacuo. Crystalline $\alpha-d$-mannose usually separates as the solution becomes concentrated. The evaporation is continued until a massecuite is obtained, whereupon evaporation is stopped and the crystals are separated. If crystallization does not occur spontaneously, the thick sirup is diluted with $200 \mathrm{ml}$ of methyl alcohol and seeded with $\alpha-d$-mannose. About $250 \mathrm{~g}$ of crystalline mannose separates in the first crop and approximately $100 \mathrm{~g}$ additional may be obtained by evaporating the mother liquors to a thick sirup containing about 85-percent total solids. The thick sirup is taken up in methyl alcohol and brought to crystallization by seeding with $\alpha$-d-mannose.

Recrystallization.-One hundred grams of crude mannose is dissolved in $100 \mathrm{ml}$ of water. After the addition of a few drops of acetic acid and $5 \mathrm{~g}$ of a decolorizing carbon, the solution is filtered and evaporated in vacuo to a heavy sirup $\left(n_{D}^{20}=1.511\right)$. The sirup is mixed with $50 \mathrm{ml}$ of warm methyl alcohol, followed by $200 \mathrm{ml}$ of a mixture containing equal volumes of methyl and isopropyl alcohols. The sirup is decanted from any gummy material, filtered, if necessary, and then seeded with about $0.5 \mathrm{~g}$ of $\alpha$ - $d$-mannose and allowed to crystallize, preferably while kept in motion. In the course of 1 or more days, about $75 \mathrm{~g}$ of the crystalline sugar separates. By concentrating the mother liquor and repeating the process, nearly all of the mannose can be separated in the crystalline state.

In 4-percent aqueous solution $\alpha$ - $d$-mannose gives $[\alpha]_{D}^{20}=+29.3$ initially, changing in the course of several hours to an equilibrium value of +14.2 .

[1] R. Reiss, Ber. deut. chem. Ges. 22, 609 (1889).

[2] E. Fischer and J. Hirschberger, Ber. deut. chem. Ges. 22, 3218 (1889).

[3] C. S. Hudson and H. L. Sawyer, J. Am. chem. Soc. 39, 470 (1917).

[4] E. P. Clark, J. Biol. Chem. 51, 1 (1922).

[5] T. S. Harding, Sugar 25, 583 (1923).

[6] P. M. Horton, J. Ind. Eng. Chem. 13, 1040 (1921).

[7] C. S. Hudson and E. L. Jackson, J. Am. Chem. Soc. 56, 958 (1934).

WASHington, October 25, 1940.

\footnotetext{
${ }^{3}$ Commerical 99-percent isopropyl alcohol and technical synthetic methyl alcohol are suitable for this preparation.
} 